\title{
Зак А.3.
}

\section{Условия формирования рефлексии способов решения задач у второклассников}

Психологический институт Российской академии образования (Россия, Москва)

doi: $10.18411 / j-07-2019-18$

idsp: ljournal-07-2019-18

\section{Аннотация}

В статье раскрывается содержание исследования, в котором изучаются возможности формирования у второклассников метакогнитивных умений, связанных с рефлексией способов решения задач. Было показано, что регулярное решение детьми поисковых задач разного типа (на 30 занятиях в течение учебного года по авторской программе «Понимание 1») существенно способствует формированию у них изучаемых умений: результаты решения диагностических задач детьми экспериментальной группы статистически значимо различаются с результатами детей контрольной группы.

Ключевые слова: второклассники, программа «Понимание 1», диагностическая методика «Обмены».

\section{Abstract}

The article reveals the content of the study, which examines the possibility of forming in second-graders metacognitive skills related to the reflection methods of solving problems. It was shown that the regular solution of different types of search tasks by children (at 30 lessons during the school year according to the author's program "Understanding 1") contributes significantly to the development of their studied skills: the results of solving the diagnostic problems by children of the experimental group differ significantly from the results of the children of the control group.

Key words: second graders, the program "Understanding 1", diagnostic method "Exchanges".

Настоящая работа посвящена исследованию условий развития метакогнитивных умений, связанных с рефлексией способов решения задач у второклассников.

Важно отметить, что изучение метакогнитивных умений у школьников активно проводится в последние годы. Так, при изучении метакогнитивных умений как условий освоения школьных программ одни авторы разрабатывают содержание метакогнитивных умений, способствующих самоконтролю школьников при освоении содержания концептуальных текстов [5], другие - выявляют позитивную роль этих умений в понимании младшими школьниками текстов, отражающих природные процессы и закономерности [8].

При рассмотрении условий формирования метакогнитивных умений в процессе обучения в школе серьезное внимание уделяется педагогическим подходам, которые помогают детям планировать применение разных типов мышления к различным задачам, а также повышать эффективность своего мышления при неудачах [11].

С одной стороны, существенным условием развития метакогнитивных умений у младших школьников при усвоении школьных предметов рассматривается метакогнитивная среда [7]. С другой стороны, важную роль в формировании метакогнитивных умений для анализа и оценки содержания и формы дискуссий у детей играет активная диалогическая среда обучения наряду с организацией коллективных дискуссий играет [6]. Обучение детей некоторым методам решения математических задач также создает благоприятные условия для развития метакогнитивных умений [3]. 
Анализ метакогнитивных умений как показателей успешного обучения выявил их прогностическую эффективность для оценки результатов обучения [10], поскольку метакогнитивный мониторинг позволяет получать более точные и полные результаты обучения у детей начальной школы [9]. Это связано с тем, как отмечается в исследовании [4], что рефлексивные характеристики действий учеников выступают показателями успешного выполнения школьных заданий.

Анализ содержания рассмотренных исследований показывает, что развитие метакогнитивных умений исследователи связывают со школьным образованием и, соответственно, с учебным материалом. Кроме того, метакогнитивные умения общего характера, - связанные с управлением мышлением в целом (планирование, мониторинг, оценка), - привлекают больше внимания, чем частные метакогнитивные умения, связанные с рефлексией способов решения задач. Однако, что изучение таких метакогнитивных умений, особенно у детей начальной школы, необходимо, так как умение различать и обобщать способы решения задач является важным условием успешного обучения в средней школе.

Мы считаем, что не только учебный материал (как в рассматриваемых исследованиях), но и неучебный материал может выступать условием формирования метакогнитивных умений, связанных с рефлексией способа решения проблем и его обобщением. В первом случае детям обычно предлагают учебные ЗАДАЧИ, РЕШЕНИЕ которых основывается на соответствующих предметных знаниях, недостаток которых приводит к неудаче. Во втором случае детей просят решать нестандартные поисковые задачи, решение которых не связано с предварительным приобретением знаний. Это обстоятельство создает возможности для успешных действий тем детям, кто имеет опыт неудач при решении учебных задач, поскольку решение поисковых неучебных задач не связано с академической неудачей. В этой ситуации у таких детей появляется возможность действовать более уверенно, чем при решении задач по учебным дисциплинам.

Основной вопрос нашего исследования состоял в том, чтобы выяснить, может ли решение детьми поисковых задач, имеющих неучебное содержание, способствовать формированию метакогнитивных умений, связанных с рефлексией способов решения задач. Для решения этого вопроса была разработана программа «Понимание 1», которая позволяет проводить 30 занятий (один раз в неделю, сентябрь - май), в течение которых детям предлагается решить 30 типов поисковых задач неучебного содержания.

Исследование было направлено на определение характера влияния занятий по программе «Понимание 1» на формирование рефлексии способов решения задач у второклассников. В исследовании участвовало 109 учеников: 53 - контрольная группа, 56 - экспериментальная группа. Предполагалось, что занятия по программе начальной школы для второго класса и занятия по программе «Понимание 1» обеспечат более интенсивное формирование рефлексии способов решения задач, чем только занятия по программе начальной школы, - в частности, прогнозировалось, что результаты экспериментальной группы будут статистически значимо отличаться от результатов контрольной группы.

Исследование включало три этапа. На первом этапе дети контрольной и экспериментальной групп решали задачи методики «Обмены» для определения сформированности рефлексивных действий, связанных с обобщением способов решения задач. На втором этапе экспериментальная группа в течение учебного года (сентябрь - май) участвовала в 30 занятиях по программе «Понимание 1» (один раз в неделю). На третьем этапе дети обеих групп снова решали те же задачи методики «Обмены», что и на первом этапе.

Программа «Понимание 1» предназначена для проведения 30 уроков на основе 30 типов поисковых задач неучебного содержания: 9 типов задач на сравнение схематически представленных объектов (компаративные задачи), 8 типов сюжетно- 
логических задач, 13 типов задач, связанных с перемещением воображаемых персонажей по определенным правилам (маршрутные задачи). На каждом занятии дети решают задачи одного типа.

Программа включала следующие 9 типов компаративных задач.

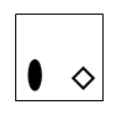

1

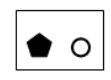

2

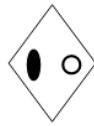

3

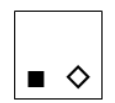

4

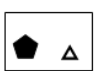

5

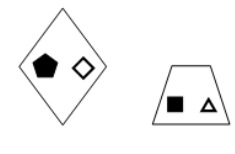

Рисунок 1. Четырехугольники.

Тип 1, например: «Рассмотрим четырехугольники 1, 3, 6. Какой четырехугольник похож по форме на четырехугольник 6?»

Тип 2, например: «Четырехугольники 2, 3, 5. Какой четырехугольник имеет одинаковый признак с четырехугольником 5?»

Тип 3, например: «Четырехугольники 2, 5, 6. Какой четырехугольник, 5 или 6, имеет больше одинаковых признаков с четырехугольником 2?»

Тип 4, например: «Четырехугольники 2, 3, 6. Какой четырехугольник, 2 или 3, имеет такую же форму, как у четырехугольника 6, и такую же темную фигуру, как у четырехугольника 1?»

Тип 5, например: «Четырехугольники 1, 3, 6. Какой четырехугольник, 1 или 3, имеет один одинаковый признак с четырехугольником 1 и один одинаковый признак с четырехугольником 2?»

Тип 6, например: «Четырехугольники 1 - 7. Четырехугольники 1 и 6 имеют один одинаковый признак. Какие два четырехугольника - 2 и 3 или 1 и 4 - имеют больше одинаковых признаков, чем четырехугольники 1 и 6 ? »

Тип 7, например: «Четырехугольники 1 - 7. Какой четырехугольник, 3 или 5, похож по форме на четырехугольник 2 , имеет темную фигуру, как у четырехугольника 6, и светлую фигуру, как у четырехугольника 7?»

Тип 8, например: «Четырехугольники 1 - 7. Какой четырехугольник, 4 или 3, имеет один одинаковый признак с четырехугольником 1 , один одинаковый признак с четырехугольником 2 и один одинаковый признак с четырехугольником 6?»

Тип 9, например: «Четырехугольники 1 - 7. Четырехугольники 2, 5, 6 имеют один одинаковый признак. Какие три четырехугольника $-2,3,5 ; 1,4,6$ или 5, 6, 7, имеют такое же количество одинаковых признаков, как у четырехугольников 2, 5, 6? »

На каждом занятии дети решают 3 варианта задач одного типа. Рассмотрим эти варианты на примере задач первого типа.

Вариант 1, например: «Рассмотрим четырехугольники 2, 3, 6. Какой четырехугольник похож по форме на четырехугольник 6?»

Вариант 2. Сначала ученикам дается, например, такая задача: «Дима, Лиза и Даша решали задачу: «Даны четырехугольники 1 - 6. Какой четырехугольник имеет такую же светлую фигуру, как у четырехугольника 2?» Ответы: (а) четырехугольник 1, (б) четырехугольник 3, (в) четырехугольник 4». Лиза выбрала ответ (а). Дима - ответ (б). Даша - ответ (в)».

Затем учеников спрашивают: «Кто из детей, - Лиза, Дима или Даша, - сделал правильный выбор?»

Вариант 3. Сначала ученикам дается, например, такая задача: «Федя, Маша и Света, решали задачу, - «Даны четырехугольники 1 - 6. Какой четырехугольник имеет такую же темную фигуру, как у четырехугольника 5?» Ответы: (а) четырехугольник 2, (б) четырехугольник 4, (в) четырехугольник 6. Федя выбрал ответ (а). Маша - ответ (б). Света - ответ (в)». 
Затем учеников спрашивают: «Кто из детей, - Федя, Маша или Света, - сделал неправильный выбор?»

Программа включала следующие 8 типов сюжетно-логических задач.

Тип 1, например: «Ваня, Лиза и Боря переплывали реку. Ваня плыл быстрее, чем Лиза. Лиза плыла быстрее, чем Боря. Кто плыл быстрее всех?»

Тип 2, например: «Слова НА, НУ, ТУ - разного цвета. Синее и розовое слова имеют одинаковую первую букву, розовое и красное - одинаковую вторую букву. Какое слово синее?»

Тип 3, например: «Элла и Лара - разного возраста. Через много лет Элла будет немного старше Лары. Кто из девочек моложе?»

Тип 4, например: «Петя, Алик и Саша отправили письма: двое в Уфу, один в Бердянск. Петя и Алик, Алик и Саша отправили письма в разные города. Куда Петя послал письмо?»

Тип 5, например: «Три слова написали синей, красной и серой краской: CBET, PОЗА, МОРЕ. Синее слово слева от красного, а серое - справа от красного. Какого цвета слово РОЗА?»

Тип 6, например: «У Димы и Кати были кубики с буквами. Сначала Дима составил слово РОТ. Затем он переставил буквы и стало слово ТОР. Катя сначала составила слово «ТИК», а затем переставила буквы так же, как Дима. Какое слово получилось у Кати?»

Тип 7, например: «Аня, Даша и Лиза жили в разных домах. Дом № 1 - высокий и каменный, дом № 2 - высокий и деревянный, дом № 3 - низкий и каменный. Дома Даши и Лизы - высокие, дома Лизы и Ани - каменные. В каком доме жила Лиза, - №1, №2 или №3?»

Тип 8, например: «Гена, Дима и Олег играли на музыкальных инструментах. Кто-то играл на трубе, кто-то - на флейте, кто-то - на скрипке. Олег не играл на скрипке, Дима не играл на флейте и скрипке. На каком инструменте играл Гена?»

На каждом занятии дети решают 3 варианта задач одного типа. Рассмотрим эти варианты на примере задач первого типа.

Вариант 1, например: «Даша, Лиза и Боря переплывали реку. Даня плыл быстрее, чем Лиза. Лиза плыла быстрее, чем Боря. Кто плыл быстрее всех?»

Вариант 2. Сначала ученикам дается, например, такая задача: «Витя, Лара и Саша решали задачу, - «Даня, Лиза и Боря переплывали реку. Даня плыл быстрее, чем Лиза. Лиза плыла быстрее, чем Боря. Кто плыл медленнее всех?» Ответы: (а) Даня, (б) Лиза, (в) Боря». Витя выбрал ответ (а). Лара - ответ (б). Саша - ответ (в)».

Затем учеников спрашивают: «Кто из детей, - Витя, Лара или Саша, - сделал правильный выбор?»

Вариант 3. Сначала ученикам дается, например, такая задача: «Катя, Вася и Коля решали задачу, - «Дима, Лена и Витя прыгали в высоту. Дима прыгнул выше, чем Лена. Дима прыгнул ниже, чем Витя. Кто прыгнул выше всех?» Ответы: (а) Дима, (б) Лена, (в) Витя». Катя выбрала ответ (а). Вася - ответ (б). Коля - ответ (в)».

Затем учеников спрашивают: «Кто из детей, - Катя, Вася или Коля, - сделал неправильный выбор?»

Программа включала следующие 13 типов маршрутных задач.

\begin{tabular}{|c|c|c|c|c|}
\hline $\mathrm{A}$ & Б & $\mathrm{B}$ & $\Gamma$ & Д \\
\hline $\mathrm{E}$ & Ж & 3 & И & К \\
\hline Л & $\mathrm{M}$ & $\mathrm{H}$ & $\mathrm{O}$ & $\Phi$ \\
\hline $\mathrm{P}$ & $\mathrm{C}$ & $\mathrm{T}$ & $\mathrm{y}$ & Ч \\
\hline $\mathrm{X}$ & Ц & Ч & Ш & \\
\hline
\end{tabular}

Рисунок 2. Игровое поле. 
Тип 1, например: «Какие два шага сделала утка, чтобы добраться от Л к Т?»

Правило: 1) «Утка», воображаемый персонаж, перемещается по буквам в клетках игрового поля; 2) особенности ее перемещений: (а) она может шагать прямо к соседней букве: по вертикали (например, от Н к Т или к 3) и по горизонтали (например, от Н к М или к О); (б) она может шагать к соседней букве наискось, - по диагонали (например, от Н к Ж или к И или к С или к У); 3) утка не может делать два одинаковых шага подряд, - два прямых шага или два шага наискось. Решение: Л... М... Т.

Тип 2, например: «Какие два прыжка сделал заяц, чтобы добраться от Л к Д?»

Правило: 1) «Заяц», воображаемый персонаж, перемещается по буквам в клетках игрового поля; 2) особенности ее перемещений: (а) он прыгает прямо, то есть через букву по вертикали (например, от Н до В или к Ч) и по горизонтали (например, от Н до Л или к П); (б) он прыгает наискось, - по диагонали, например: от Н к А или к Д или к $\mathrm{X}$ или к Щ; 3) заяц не может делать два одинаковых прыжка подряд, - два прямых прыжка или два прыжка наискось. Решение: Л... Н... Д.

Тип 3, например: «Какие два прыжка сделала лиса, чтобы добраться от М к Ф?»

Правило: 1) «Лиса», воображаемый персонаж, перемещается по буквам в клетках игрового поля; 2) особенности ее перемещений: она прыгает через клетку (например: от Н к Е или к Б или к Г или к К или к Ф или к Ш или к Ц или к Р). Решение: М... И...Ф.

Тип 4, например: «Какие два перемещения нужно сделать утке и зайцу, чтобы добраться от Ж к Ф?» Правило: утка ходит только прямо, заяц прыгает только наискось. Решение: Ж... З...Ф.

Тип 5, например: «Какие два перемещения нужно сделать утке и зайцу, чтобы добраться от 3 к Ц?» Решение: 3... М... Ц. Правило: утка ходит только наискось, заяц прыгает только прямо. Решение:

Тип 6, например: «Какие два перемещения нужно сделать утке и лисе, чтобы добраться от Б к К?» Правило: утка ходит только прямо. Решение: Б... В... К.

Тип 7, например: «Какие два перемещения нужно сделать утке и лисе, чтобы добраться от Г к С?» Правило: утка ходит только наискось. Решение: Г... 3... С.

Тип 8, например: «Какие два перемещения заяц и лиса должны сделать, чтобы добраться от Т к Д?» Правило: заяц прыгает только прямо. Решение: Т... З... Д.

Тип 9, например: «Какие два перемещения заяц и лиса должны сделать, чтобы добраться от Ж к Ц?» Правило: заяц прыгает только наискось. Решение: Ж... У... Ц.

Тип 10, например: «Какие четыре перемещения должны сделать поочередно утка и заяц, чтобы добраться от Л к К?» Правило: утка ходит прямо и наискось, заяц прыгает прямо и наискось. Решение: Л... М... Ш... Ф... К.

Тип 11, например: «Какие четыре перемещения должны сделать поочередно утка и лиса, чтобы добраться от Е к Г?» Правило: утка ходит прямо и наискось. Решение: Е... М... У... П... Г.

Тип 12, например: «Какие четыре перемещения должны сделать поочередно заяц и лиса, чтобы добраться от А к У?» Правило: заяц прыгает прямо и наискось. Решение: А... Л... Т... К... У.

Тип 13, например: «Какие три перемещения должны сделать поочередно утка, заяц и лиса, чтобы добраться от Е к Ц?» Правило: утка ходит прямо и наискось, заяц прыгает прямо и наискось. Решение: Е... Ж... У... Ц.

На каждом занятии дети решают 3 варианта задач одного типа. Рассмотрим эти варианты на примере задач первого типа.

Вариант 1, например: «Какие два шага сделала утка, чтобы добраться от И к Ф?»

Вариант 2. Сначала ученикам дается, например, такая задача: «Игорь, Миша и Денис решали задачу, - «Какие три шага сделала утка: (a) $\mathrm{M}-\mathrm{H}$ - И - Д, (b) $\mathrm{M}-3$ - И - Д или (в) $\mathrm{M}-3-\Gamma-$ Д, чтобы добраться от М к Д?» Миша выбрал ответ (а). Игорь ответ (б). Денис - ответ (в)». 
Затем учеников спрашивают: «Кто из детей, - Игорь, Миша или Денис, - сделал правильный выбор?»

Вариант 3. Сначала ученикам дается, например, такая задача: «Вова, Гена и Вика решали задачу: «Какие три шага сделала утка: (а) $\mathrm{M}-\mathrm{T}-\mathrm{У}-\Phi$, (б) $\mathrm{M}-\mathrm{H}-\mathrm{У}-\Phi$ или (в) М - Т - Ш - Ф, чтобы добраться от М к Ф?» Вова выбрал ответ (а). Гена - ответ (б). Вика - ответ (в)».

Затем учеников спрашивают: «Кто из детей, - Вова, Гена или Вика, - сделал неправильный выбор?»

Следует отметить назначение вариантов 2 и 3 в каждом типе задач. Такие варианты необходимы для формирования рефлексивных действий, поскольку в этих случаях ученик меняет деятельностную позицию на рефлексивную, т.е. позицию человека, который решает задачу, ученик меняет на позицию человека, который проверяет и оценивает решение задачи. образом.

30 типов задач распределяются по программе «Понимание 1» следующим

Занятие 1: маршрутные задачи (тип 1). Занятие 2: компаративные задачи (тип 1). Занятие 3: сюжетно-логические задачи (тип 1). Занятие 4: маршрутные задачи (тип 2). Занятие 5: компаративные задачи (тип 2). Занятие 6: маршрутные задачи (тип 3). Занятие 7: сюжетно-логические задачи (тип 2). Занятие 8: маршрутные задачи (тип 4). Занятие 9: компаративные задачи (тип 3). Занятие 10: сюжетно-логические задачи (тип 3). Занятие 11: маршрутные задачи (тип 5). Занятие 12: компаративные задачи (тип 4). Занятие 13: сюжетно-логические задачи (тип 4). Занятие 14: маршрутные задачи (тип 6). Занятие 15: компаративные задачи (тип 5). Занятие 16: маршрутные задачи (тип 7). Занятие 17: сюжетно-логические задачи (тип 5). Занятие 18: маршрутные задачи (тип 8). Занятие 19: компаративные задачи (тип 6). Занятие 20: сюжетно-логические задачи (тип 6). Занятие 21: маршрутные задачи (тип 9). Занятие 22: компаративные задачи (тип 7). Занятие 23: маршрутные задачи (тип 10). Занятие 24: сюжетно-логические задачи (тип 7). Занятие 25: маршрутные задачи (тип 11). Занятие 26: компаративные задачи (тип 8). Занятие 27: маршрутные задачи (тип 12). Занятие 28: сюжетно-логические задачи (тип 8). Занятие 29: маршрутные задачи (тип 13). Занятие 30: компаративные задачи (тип 9).

Каждое занятие по программе «Понимание $1 »$ состоит из трех частей. В первой части (около 15 минут) учитель вместе с учениками анализирует способы решения задач того типа, который должен осваиваться на данном занятии. Детям необходимо понять, что нужно искать в задачах этого типа и как это можно осуществить. Ученикам предоставляются средства анализа задач, а также способы управления поиском решения и контроля своих действий, что особенно важно для формирования рефлексивных действий.

Во второй части (около 30 минут) дети самостоятельно решают от 12 до 15 задач, применяя знания, полученные в первой части.

В третьей части (около 15 минут) учитель вместе с учениками проверяет решенные задачи, отмечает правильные решения и разбирает неправильные, указывая на возможные причины ошибочного результата. При этом он еще раз рассказывает о способах анализа задач и о возможностях контроля за собственными действиями при решении задач.

Диагностика метакогнитивных умений, связанных с рефлексией способов решения задач, состояла в следующем.

До и после 30 занятий по программе «Понимание 1» проводилась групповое решение задач учениками контрольной и экспериментальной групп. Детям предлагалось решать тренировочные и основные задачи методики «Обмены».

Тренировочные задачи

(два действия) 
1. Р Д С -------- С Р Д

2. МГ ДП В -------- В П ДГм

Основные задачи

(три действия)

1. А У О Е ИЮ --------- У А Е О Ю И

2. Л Т М Р С В -------- Р С В Л Т М

3. Ш Ф Ч Х Ц --------- ФШ Щ Ч Ц

Мнения об основных задачах.

1. Все три задачи похожи.

2. Все три задачи разные.

3. Задачи 1 и 2 похожи, а задача 3 отличается от них.

4. Задачи 1 и 3 похожи, а задач 2 отличается от них.

5. Задачи 2 и 3 похожи, а задача 1 отличается от них.

В начале урока детям разъяснялись формальные правила перемещения букв: одно действие состоит в одновременном обмене местами любых двух букв, например, К Р С --- Р К С или М Н П --- П Н М или В Д Т Ф --- Ф Д Т В.

Затем показывалось решение задачи в два действия, например: Л Р Г Н --- Н Г Р Л. В этой задаче первое действие состоит в обмене местами букв Л и Н, второе - в обмене букв Р и Г.

Далее ученикам сообщалось, что расположение букв слева называется начальным, справа - конечным. Указывалось, что менять буквы нужно в начальном расположении. При этом обмен букв местами следует делать мысленно, а результат обмена нужно записать как новое расположение букв в начальном расположении. Также нужно действовать и после второго и после третьего действия. Отмечалось, что смысл задач заключается в том, чтобы буквы в начальном расположении после нужного числа действий были размещены так же, как и в конечном расположении.

Затем школьникам предлагалось решить две тренировочные задачи. После коллективной проверки их решения нужно было решать основные задачи.

После решения основных задач требовалось выбрать одно из пяти мнений об основных задачах и кратко написать, почему это мнение верное.

Ученикам говорилось: «Много детей решали эти задачи. Одни дети сказали, что все задачи похожи, другие сказали, что все задачи разные. Дети третьей группы сказали, что задачи 1 и 2 похожи, а задача 3 отличается от них. Дети четвертой группы сказали, что задачи 1 и 3 похожи, а задача 2 отличается от них. Дети пятой группы сказали, что задачи 1 и 2 похожи, а задача 3 отличается от них. Все дети имеют разное мнение об этих задачах. Каждый из вас должен выбрать только одно мнение, которое вы считаете самым правильным, и написать, почему вы его выбрали».

Решение этих трех задач и выбор мнения на занятии не оценивались.

При обработке результатов решения трех задач учитывалось мнение, которое выбрал ученик, и то, как он его обосновал.

Часть детей выбрала мнение 1, обосновывая его, например, так: «... потому что везде нужно менять буквы ...».

Часть детей - мнение 2, обосновывая его, например, так: «... потому что во всех задачах буквы разные ...».

Часть детей - мнение 3, обосновывая его, например, так: «... потому что буквы в третьей задаче являются последними в алфавите, а в других задачах - не так ...».

Часть детей - мнение 4, обосновывая его, например, так: «... потому что в первой и третьей задачах меняются соседние буквы, а во второй - не так...».

Часть детей - мнение 5, обосновывая его, например, так: «... потому что в первой задаче гласные буквы ...». 
Если ученик выбрал мнение 4, указывая на сходство задач 1 и 3 и отличие от них задачи 2 по способу решения, то считалось, что при решении задач он сопоставлял способы решения и, тем самым, осуществлял содержательную рефлексию, связанную с пониманием внутренней общности задач по структуре.

Если же ученик выбрал мнение 1, 2, 3 или 5, основываясь на сходстве и различии внешних особенностей условий задачи, то считалось, что при их решении он осуществлял формальную рефлексию, поскольку не обращался к способам решения задач (подробнее о характеристиках видов рефлексии см. [1], [2]).

Количественные итоги исследования представлены в таблице.

Таблиияа

Результаты контрольной $(K)$ и экспериментальной (Э) групп в сентябре и мае

\begin{tabular}{|c|c|c|c|c|}
\hline \multirow{2}{*}{ Мнения } & \multicolumn{3}{|c|}{ Сентябь } & \multicolumn{2}{c|}{ Май } \\
\cline { 2 - 5 } & $\begin{array}{c}\text { Контрольная } \\
\text { группа }\end{array}$ & $\begin{array}{c}\text { Экспериментальная } \\
\text { группа }\end{array}$ & $\begin{array}{c}\text { Контрольная } \\
\text { группа }\end{array}$ & $\begin{array}{c}\text { Экспериментальная } \\
\text { группа }\end{array}$ \\
\hline 1 & $18(34.0 \%)$ & $19(37.5 \%)$ & $13(24.5 \%)$ & $6(10.7 \%)$ \\
\hline 2 & $14(26.4 \%)$ & $16(28.6 \%)$ & $10(18.8 \%)$ & $7(12.5 \%)$ \\
\hline 3 & $9(17.0 \%)$ & $10(14.3 \%)$ & $11(20.8 \%)$ & $12(21.4 \%)$ \\
\hline 4 & $6(11.3 \%)$ & $5(8.9 \%)$ & $11(20.8 \%)^{*}$ & $22(39.3 \%)^{*}$ \\
\hline 5 & $6(11.3 \%)$ & $6(10.7 \%)$ & $8(15.1 \%)$ & $9(16.1 \%)$ \\
\hline \multicolumn{5}{|c}{} \\
\hline
\end{tabular}

Данные, приведенные в таблице, характеризуют различия в выборе мнений 1, 2, 3,4 и 5 между детьми контрольной и экспериментальной групп до и после занятий по программе «Понимание $1 »$.

Во-первых, следует отметить количественные изменения (путем сопоставления результатов, полученных в сентябре и мае) в выборе мнения 4, характеризующего обобщение способов решения задач 1 и 3 . Это свидетельствует о реализации метакогнитивных умений, связанных с осуществлением рефлексивных действий содержательного характера.

В обеих группах число детей, выбравших это мнение, увеличилось. Например, до занятий было $11,3 \%$ таких детей в контрольной группе, после занятий $-8,9 \%$, в экспериментальной группе, соответственно: 20,8\% и $39,3 \%$, - различие этих результатов статистически значимо (при $\mathrm{p}<0,05$ ). В экспериментальной группе эта подгруппа детей увеличилась более чем в три раза, в контрольной группе - менее чем в два раза, соответственно: на 30,4\% (с 8,9\% до 39,3\%) и на 9,5\% (с 11,3\% до 20,8\%). Этот факт свидетельствует о существенном влиянии занятий по программе «Понимание 1» на формирование метакогнитивных умений, связанных с осуществлением содержательных рефлексивных действий.

Во-вторых, важно отметить количественные изменения в выборе других мнений, характеризующих формальное сходство задач 1, 2 и 3 (мнение 1), задач 2 и 3 (мнение 3 ), задач 1 и 2 (мнение 5) и формальное различие задач 1, 2 и 3 (мнение 2). Выбор этих мнений указывает на реализацию метакогнитивных умений, связанных с рефлексивными действиями внешнего, формального характера.

Число детей, выбравших утверждения 1 и 2, уменьшилось в обеих группах. До занятий эти подгруппы составили, соответственно, $37,5 \%$ и $28,6 \%$ в экспериментальной группе, $34,0 \%$ и 26,4\% в контрольной группе. После занятий эти подгруппы составили, соответственно, $10,7 \%$ и $12,5 \%$ в экспериментальной группе, $24,5 \%$ и $18,8 \%$ в контрольной группе. В экспериментальной группе уменьшение составило $26,8 \%$ и $16,1 \%$, в контрольной группе, соответственно, 10,5\% и 7,6\%. Таким образом, в экспериментальной группе число детей, считающих основные задачи 1, 2 и 3 одинаковыми или разными, уменьшилось больше, чем в контрольной группе. 
Число детей, выбравших мнения 3 и 5, увеличилось в обеих группах. До занятий эти подгруппы детей составили, соответственно, 14,3\% и 10,7\% в экспериментальной группе и $17,0 \%$ и $11,3 \%$ в контрольной группе. После занятий эти подгруппы составили, соответственно, 21,4\% и 16,1\% в экспериментальной группе и 20,8\% и $15,1 \%$ в контрольной группе. В экспериментальной группе увеличение составляет, соответственно, 7,1\% и 4,4\%, в контрольной группе - 3,8\% и 3,8\%. Таким образом, в экспериментальной группе общее число детей, которые считали основные проблемы 1 и 2, 2 и 3 одинаковыми или разными, увеличилось несколько больше, чем в контрольной группе, то есть на $11,5 \%$ и 7,6\%, соответственно.

Факты, отражающие изменения в подгруппах детей, которые выбрали мнения, характеризующие внешне, формальное сходство и различие основных задач, указывают на значительное (это особенно верно для подгрупп детей, которые выбрали утверждения 1 и 3) влияние занятий по программе «Понимание 1» на изменение знаний детей о решаемых задачах: от более общих («Основные задачи 1, 2 и 3 похожи») и («Основные задачи 1, 2 и 3 разные») до более конкретных («Основные проблемы 1 и 2 похожи, задача 3 отличается от них») и («Основные проблемы 2 и 3 похожи, задача 1 отличается от них»).

В целом, проведенное исследование подтвердило исходную гипотезу о том, что занятия по программе «Понимание 1» существенно способствует формированию метакогнитивных умений, связанных с рефлексией способов решения задач, в частности, с содержательной рефлексией. В таблице показано, что результаты экспериментальной группы статистически значимо отличаются от результатов контрольной группы.

Отмеченный итог исследования связан с четырьмя характеристиками проблемного материала программы «Понимание 1»: а) занимательное, неучебное содержание задач; б) поисковый характер задач; в) разнообразие типов задач (8 типов сюжетных и логических задач, 9 типов компаративных задач и 13 типов маршрутных задач); г) задачи каждого типа давались в трех вариантах, обеспечивающих разную позицию ребенка по отношению к задаче: деятельностную и рефлексивную.

Важными особенностями реализации программы являются особенности развивающих занятий: их общее количество, частота, продолжительность и регулярность, а также структура каждого занятия.

Так, 30 занятий проводились в течение девяти месяцев (с сентября по май) один раз в неделю. Каждое занятие длилось 60 минут и состояло из трех частей: предварительное обсуждение действий по решению задач (около 15 минут), самостоятельное решение задач (около 30 минут), завершающее обсуждение (около 15 минут).

Исследование позволило получить новую информацию об условиях формирования метакогнитивных умений, связанных с рефлексией способов решения задач у школьников второго класса (7,5 - 8 лет). Полученные данные расширяют и уточняют представления возрастной психологии о возможностях интеллектуального развития детей младшего школьного возраста.

Следует отметить, в заключение, что апробированная в исследовании программа «Понимание 1» выступает одним из возможных способов интеллектуального обогащения учебной среды, реализуемым путем включения внеклассных занятий в образовательную программу начальной школы.

$$
* * *
$$

1. Давыдов В.В. Теория развивающего обучения. М.: Интор, 1996. 436 с.

2. Зак А.З. Мышление младшего школьника.Спб.:Содействие, 2004. 828 с.

3. Desoete, A. (2007). Evaluating and improving the mathematics teaching-learning process through metacognition? Electronic Journal of Research in Educational Psychology, 5(3), 705-730. 
4. Elshout-Mohr, M., Meijer, J., van Daalen-Kapteijns, M., \& Meeus, W. (2003). A self-report inventory for metacognition related to academic tasks. Paper presented at the 10th Conference of the European Association for Research on Learning and Instruction (EARLI). Padova, Italy, 26-30 August 2003.

5. Koch, A. (2001). Training in metacognition and comprehension of physics texts. Science Education, 75, 858868.

6. Kramarski B., Mevarech Z.R. (2003). Enhancing mathematical reasoning in the classroom: The effects of cooperative learning and metacognitive training. American Educational Research Journal, 40 (1), 281-310.

7. Larkin, S. (2010). Metacognition in Young Children. Abingdon, Routledge.

8. Michalsky, T., Mevarech Z. R., Haibi. L. (2009). Elementary School Children Reading Scientific Texts: Effects of Metacognitive Instruction. The Journal of Educational Research, 102(5), 363-376.

9. Roebers,C.M.,Krebs,S. S.,Roderer,T.(2014).Metacognitive monitoring and control in elementary school children: Their interrelations and their role for test performance. Learning and Individual Differences, 29, 141149.

10. Schraw G., Crippen K.J., Hartley K.(2002). Promoting selfregulation in science education: Metacognition as part of a broader perspective on learning. Research in Science Education, 3, 111-139.

11. Swartz, R. J., Costa, A., Kallick, B., Beyer, B., \& Reagan, R. (2007). Thinking-based learning: Activating students' potential. Norwood, MA: Christopher-Gordon Publishers. 